(ntrodection

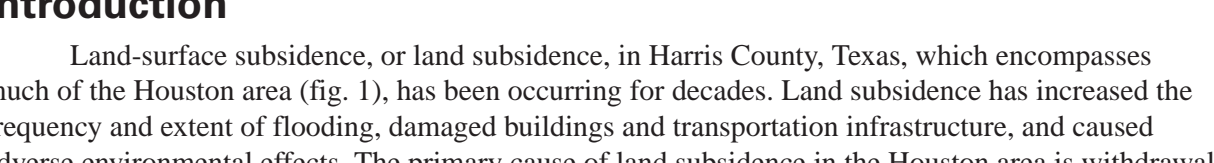

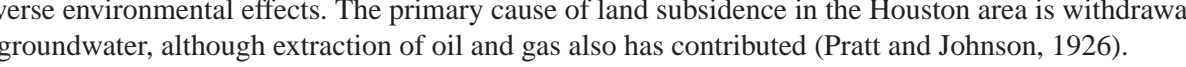

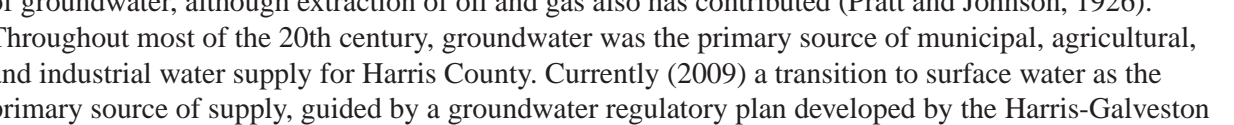

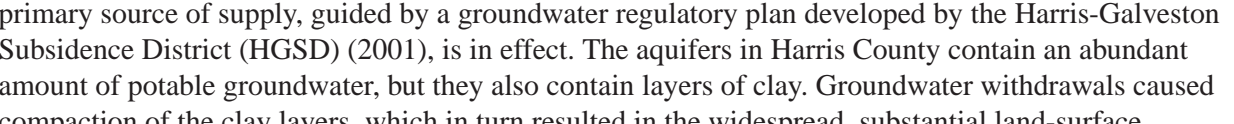

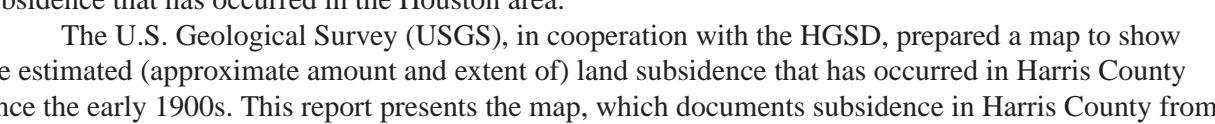

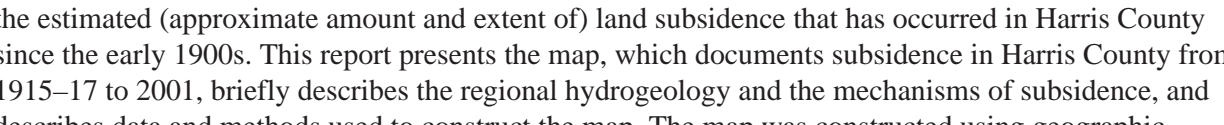

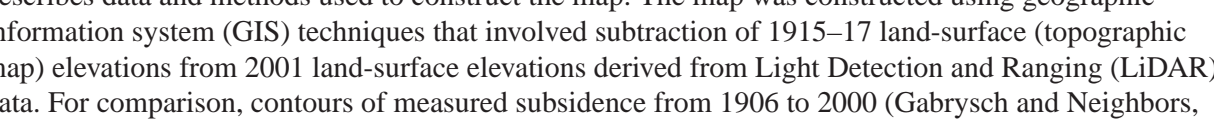

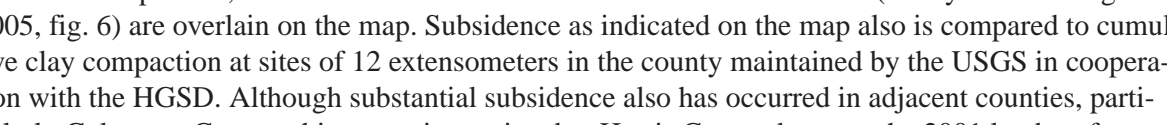

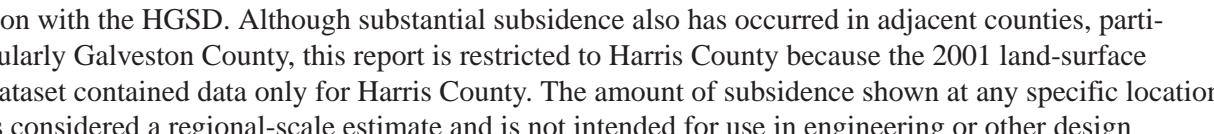

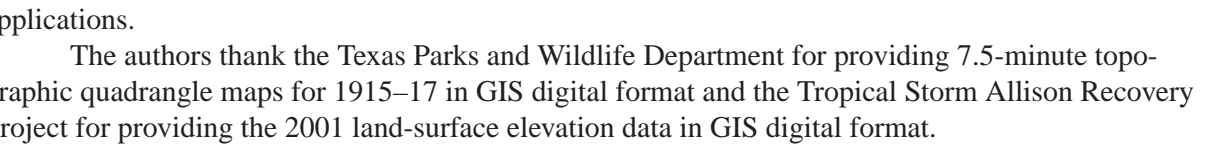
Hydrogeology

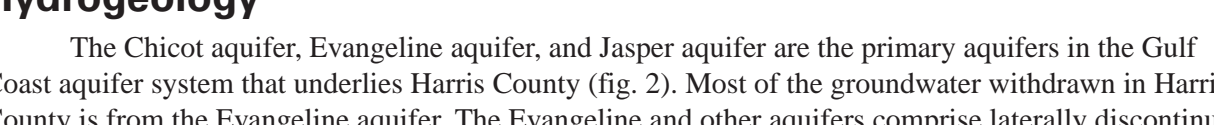

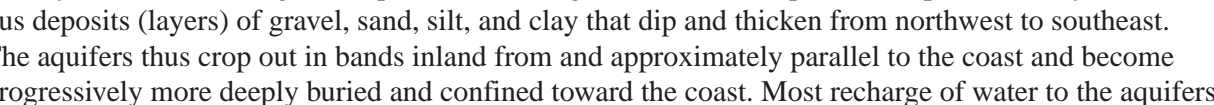

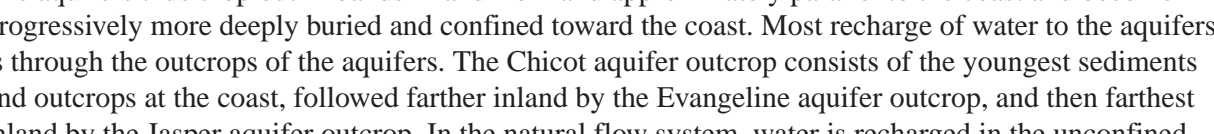

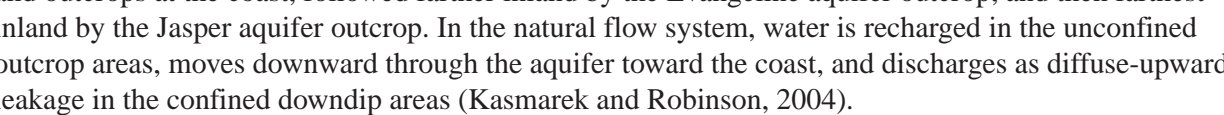
Historical Groundwater Withdrawals and Land-Surface

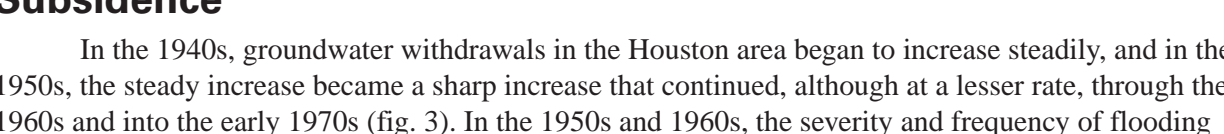

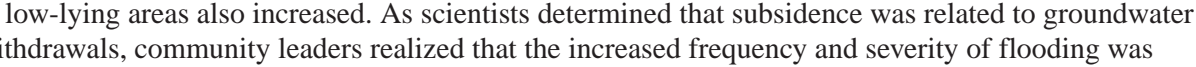

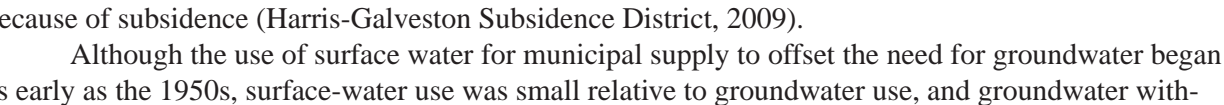

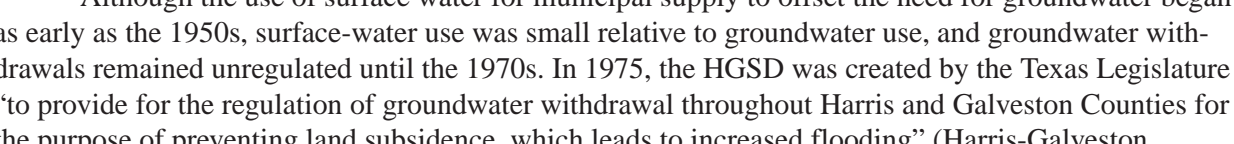

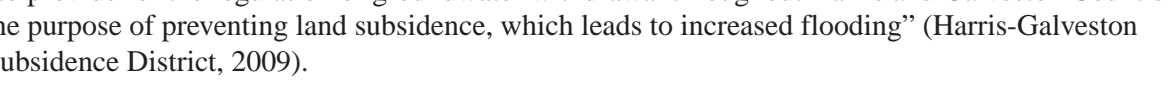

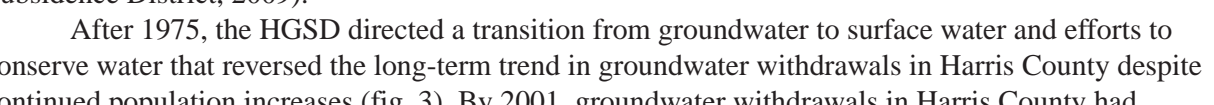

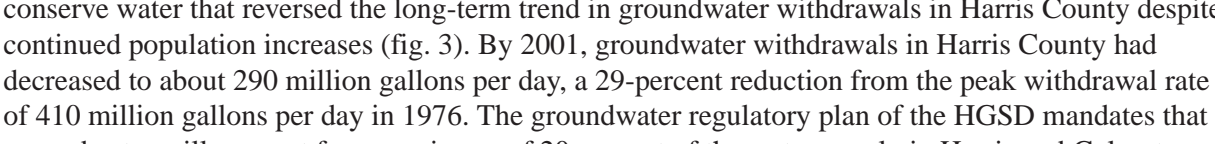

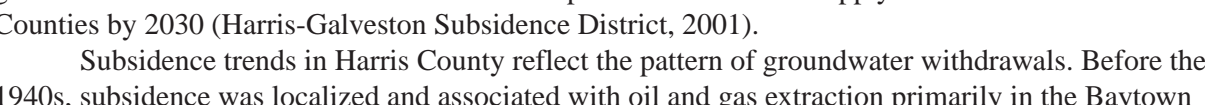

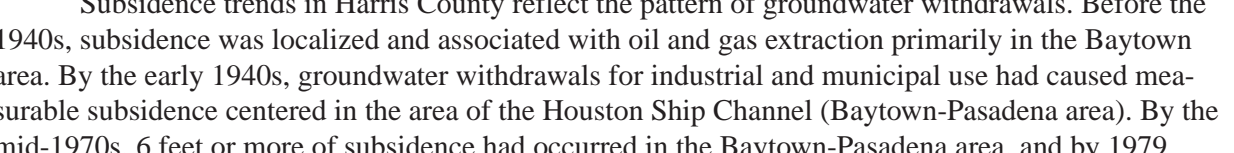

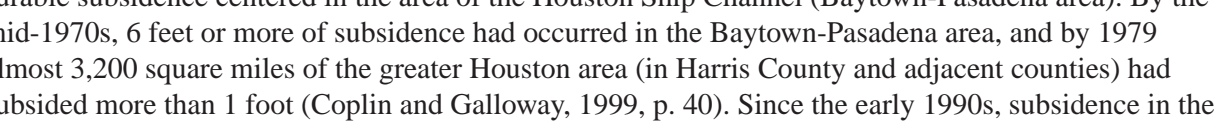

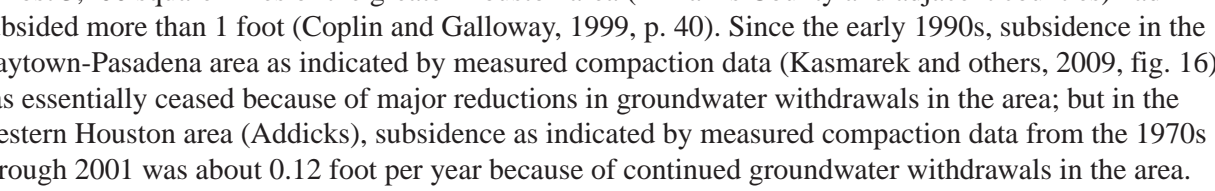

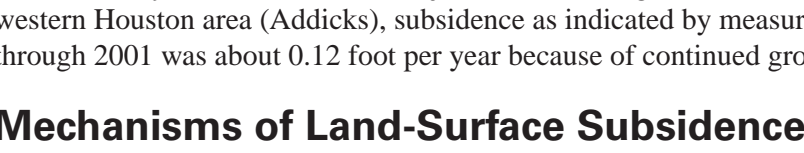

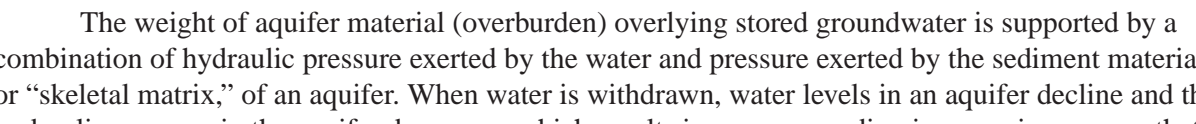

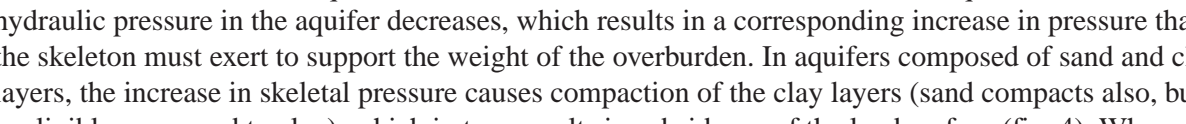

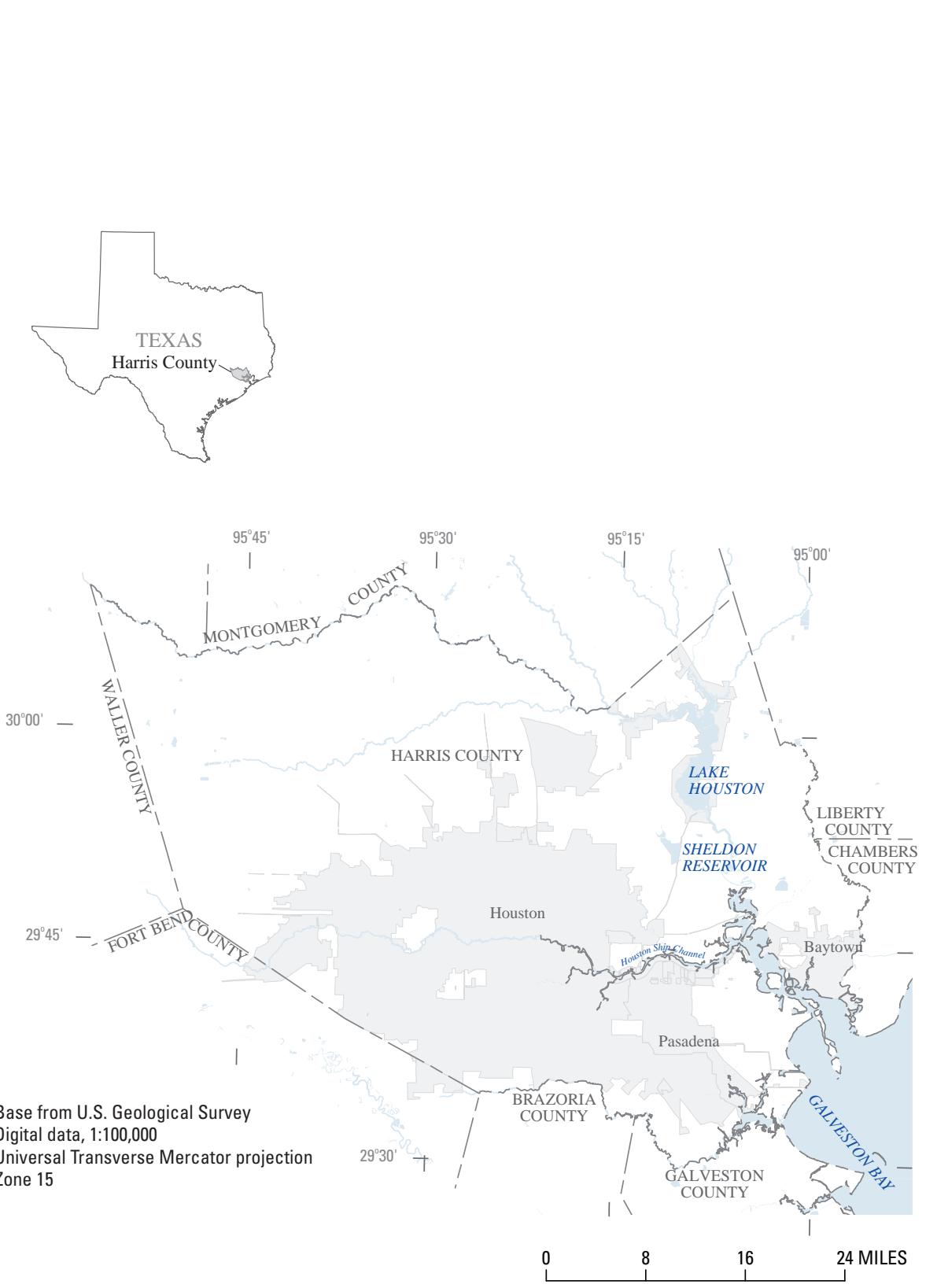

Figure 1. Location of Harris Sounty and Houston, Texas

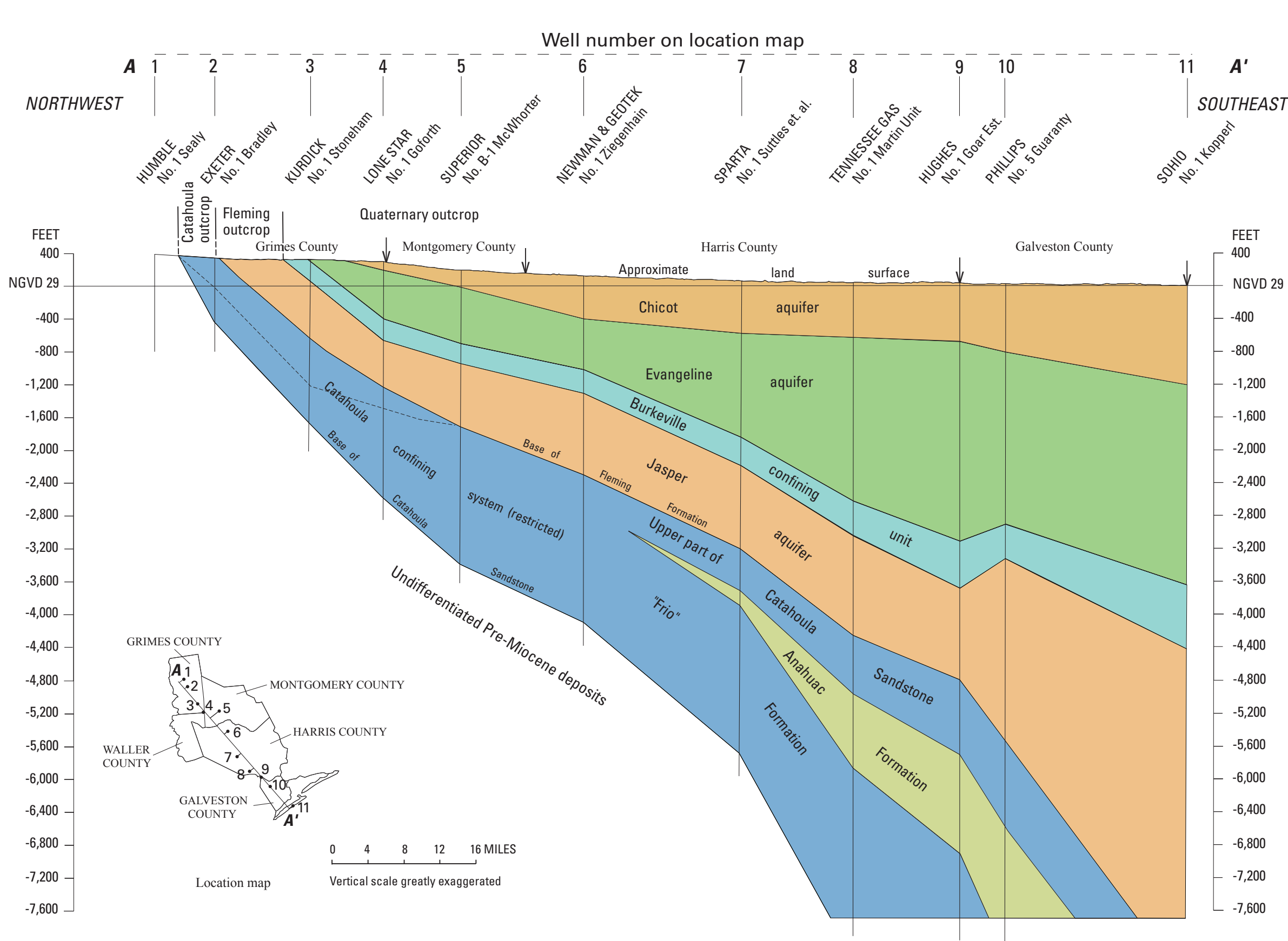

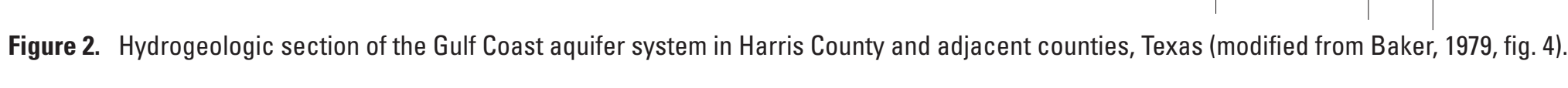

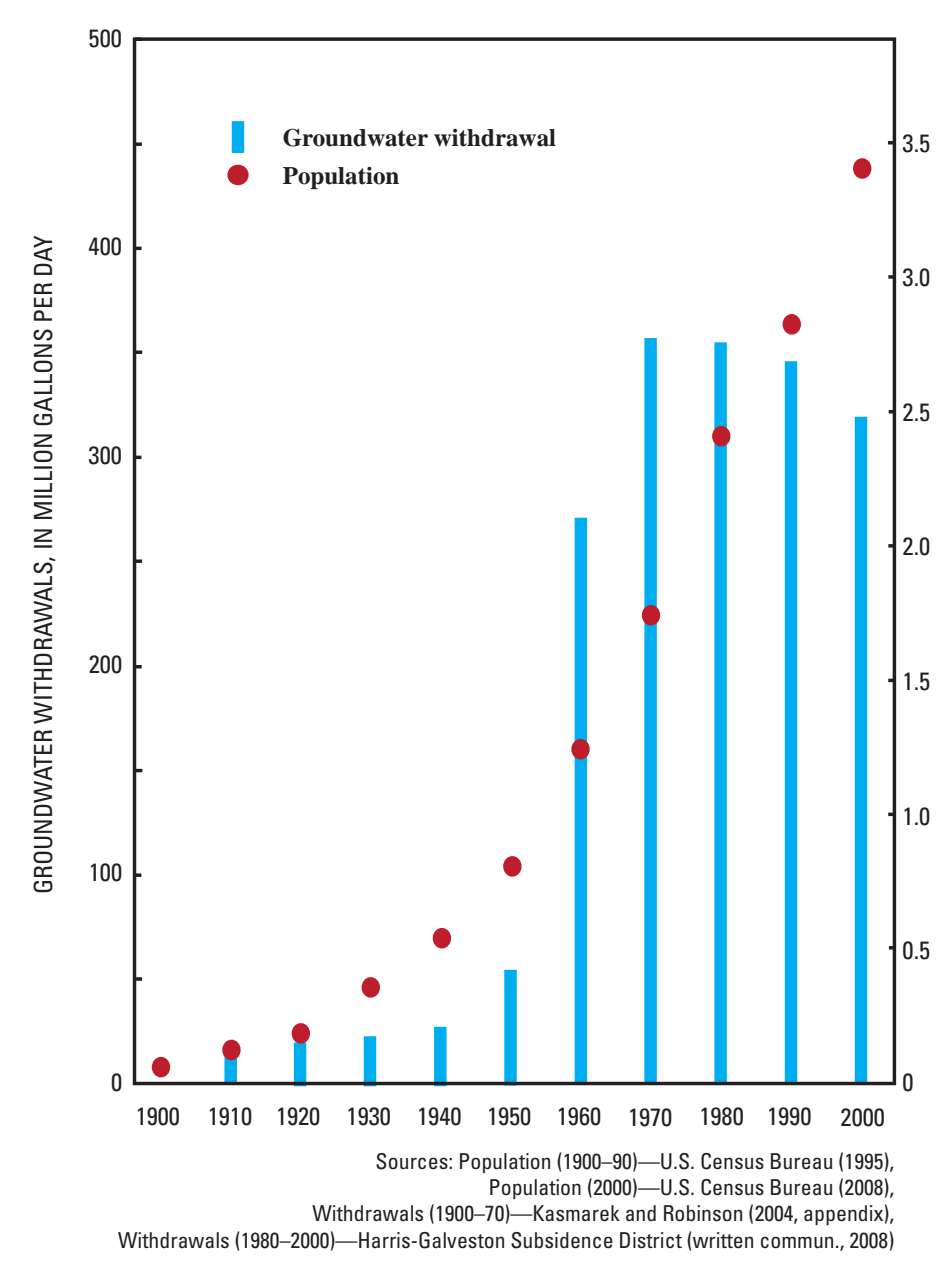

Figure 3. Trends in inroundwater
Harris County, Texas, $900-2000$.

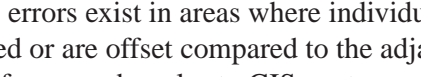

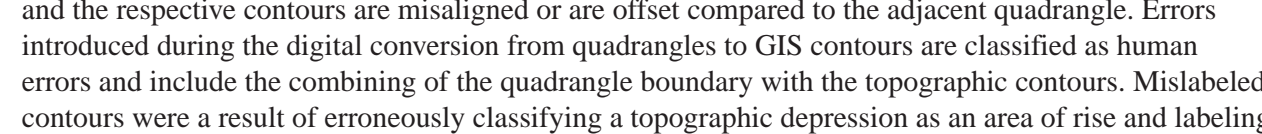

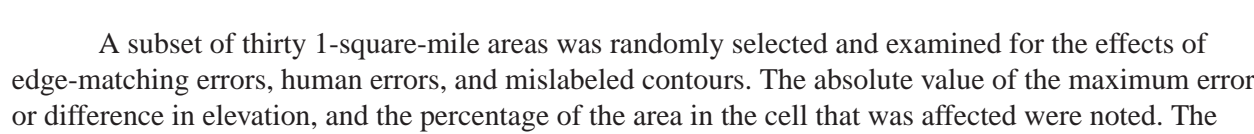

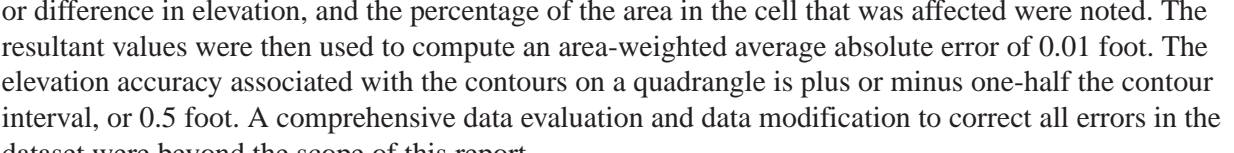

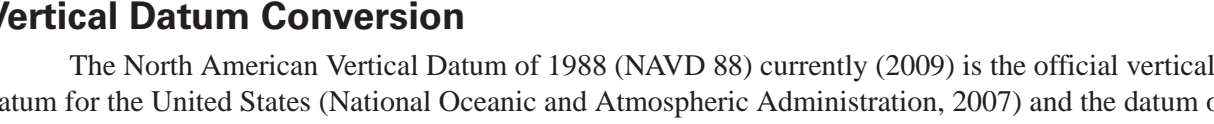

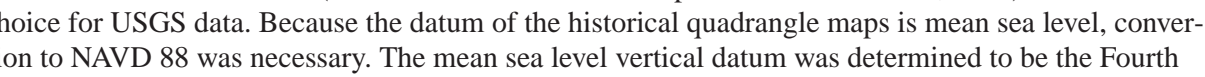

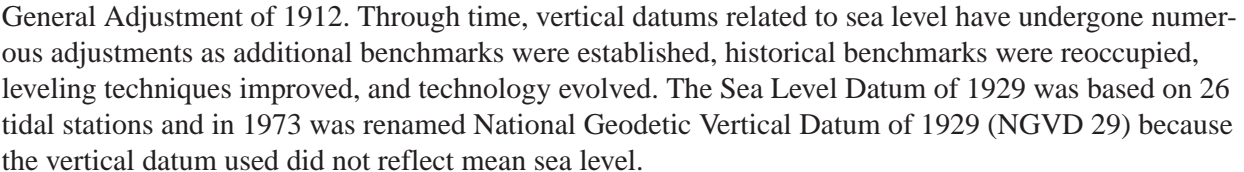

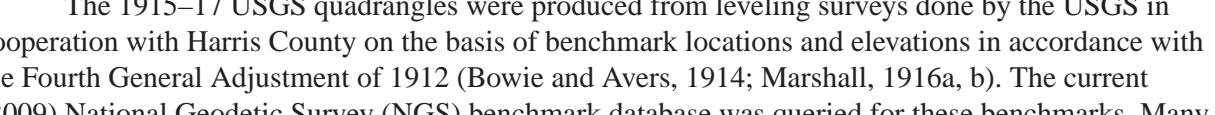

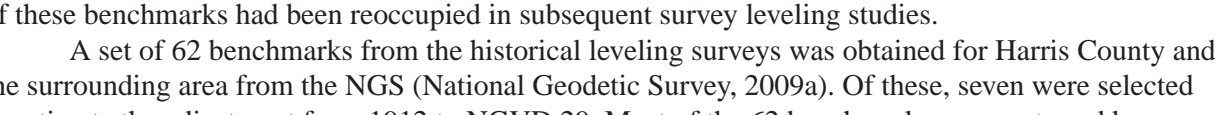

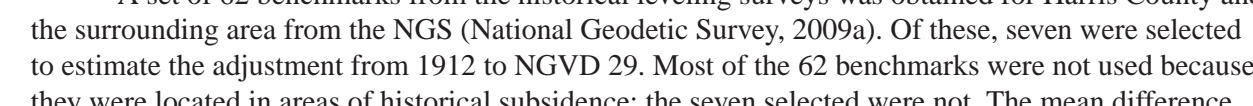

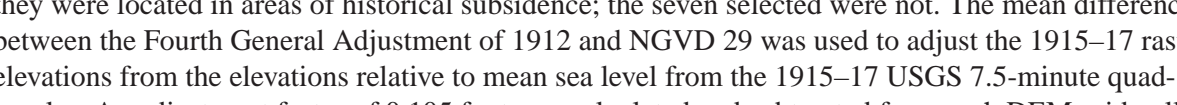

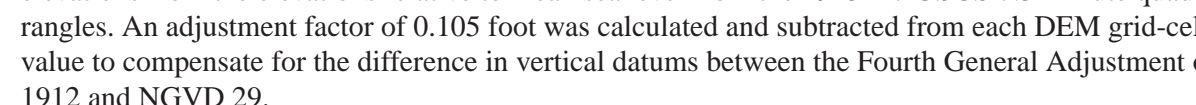

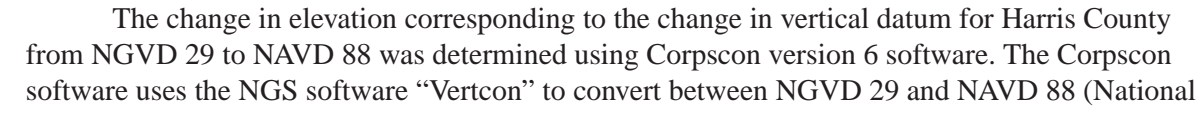

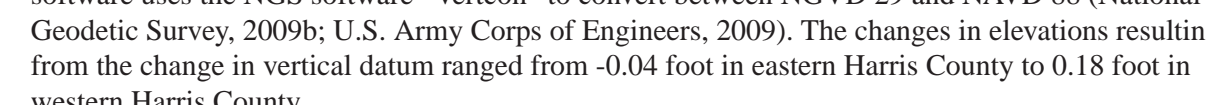

\section{Light Detection and Ranging (LiDAR) Data}

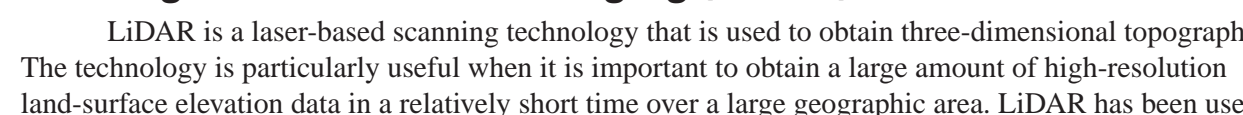

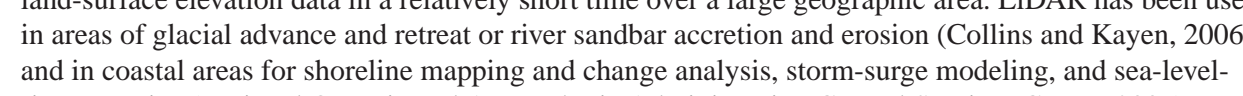

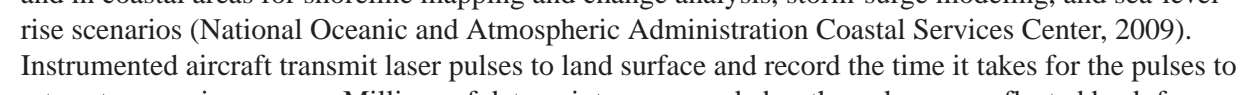

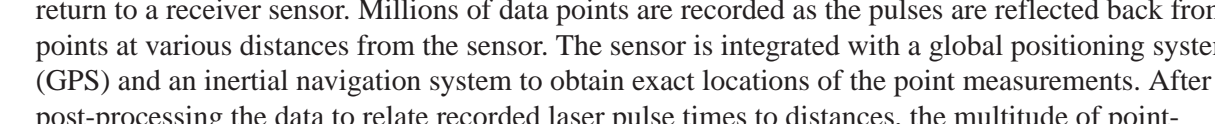

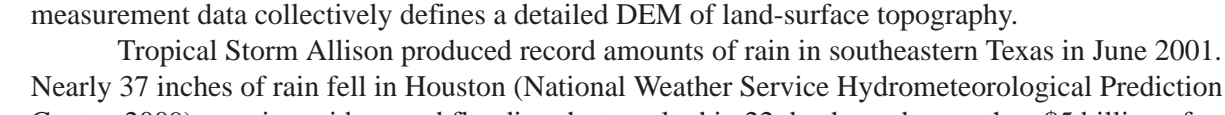

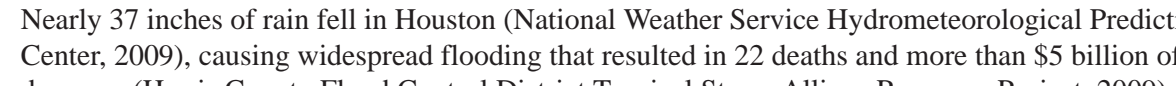

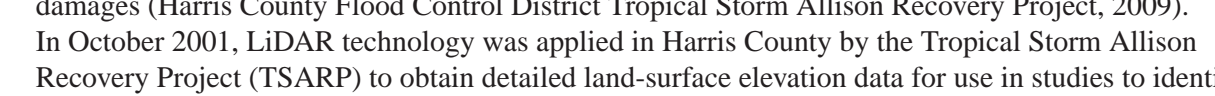

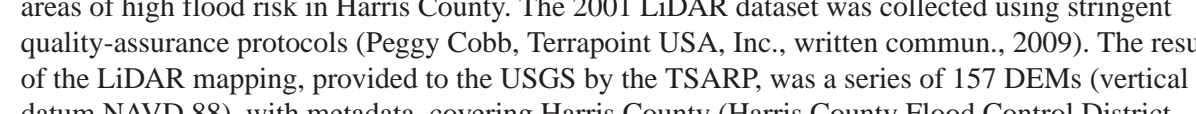

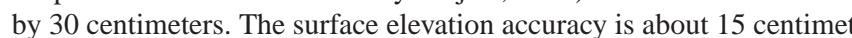

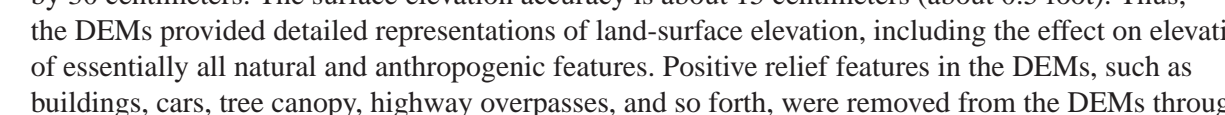

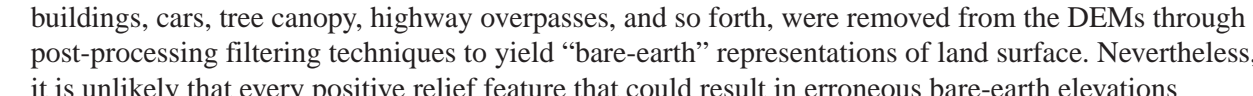

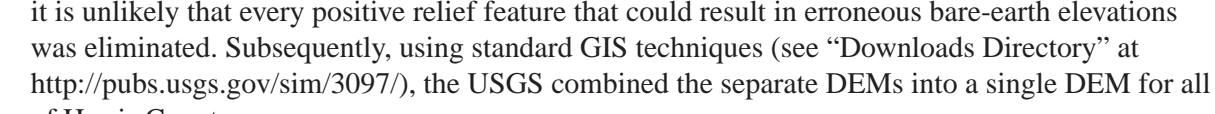

\section{Map Showing Estimated
County, $1915-17$ to 2001}

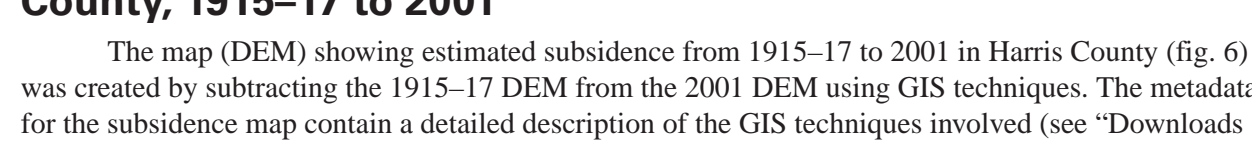

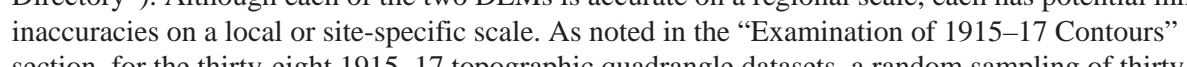

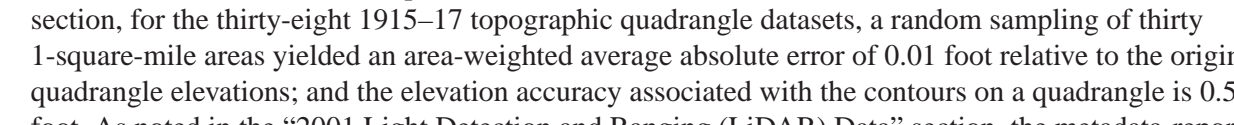

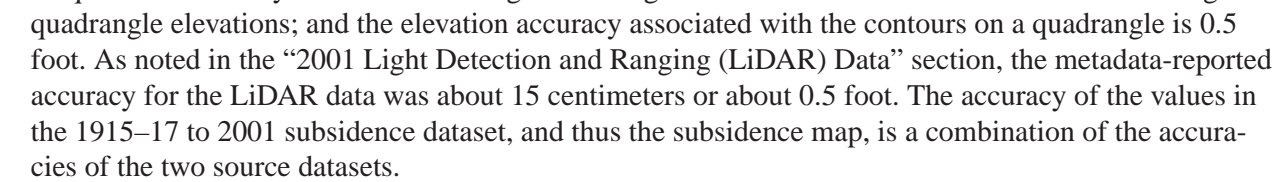

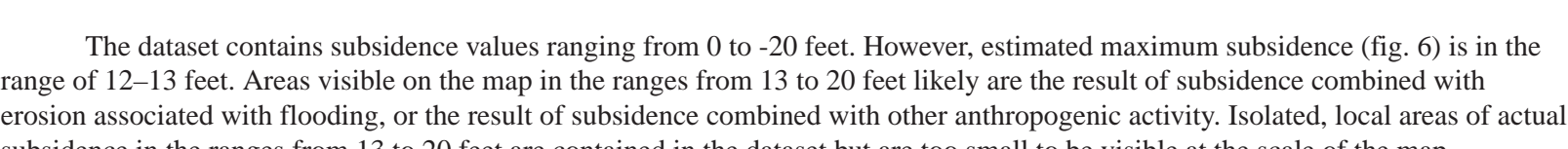

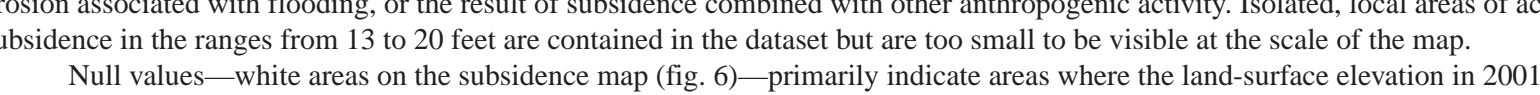

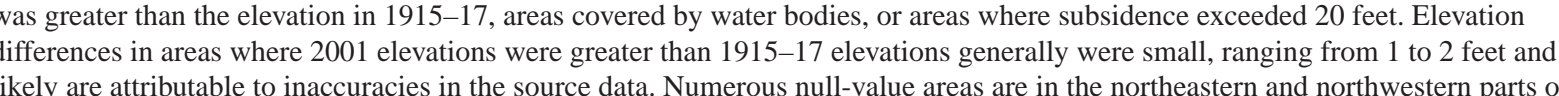

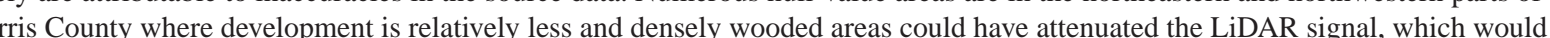

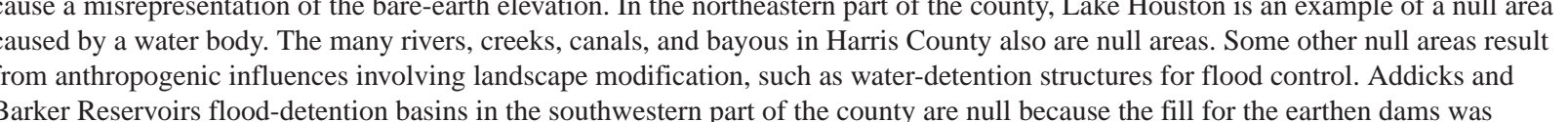

Sbsidence Map Compared with Contours of Measured Subsidence, 1906-2000

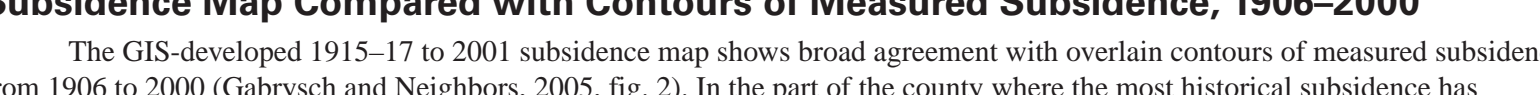

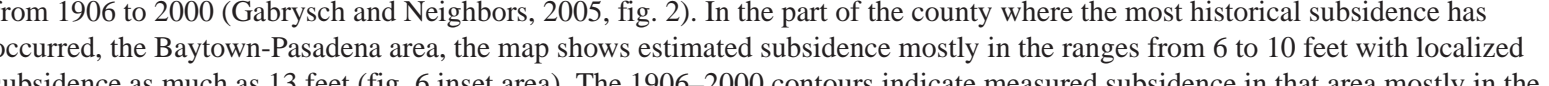

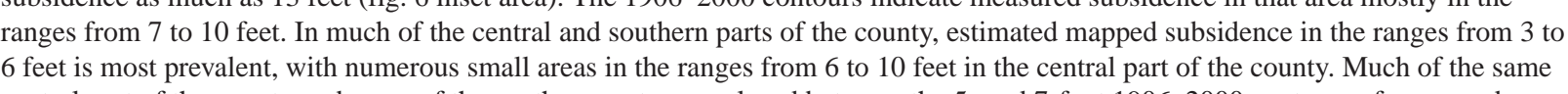

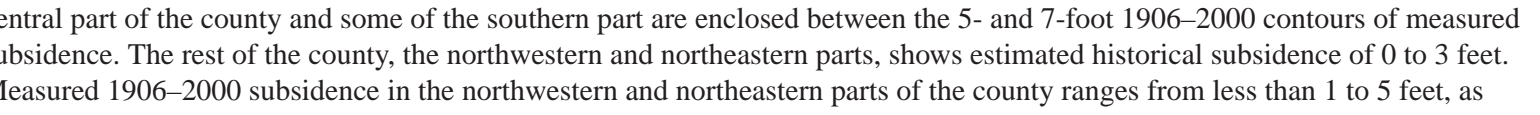

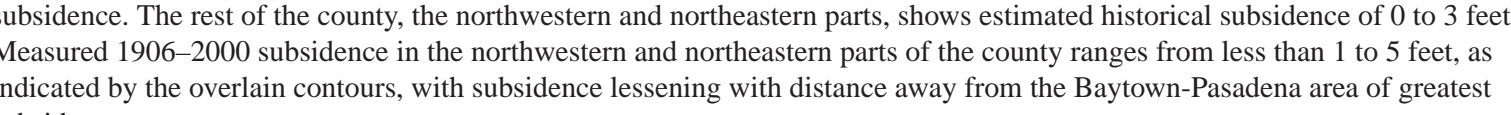

Subsidence Map Compared with Measured Cumulative Clay Compaction at 10
Extensometetr Sites

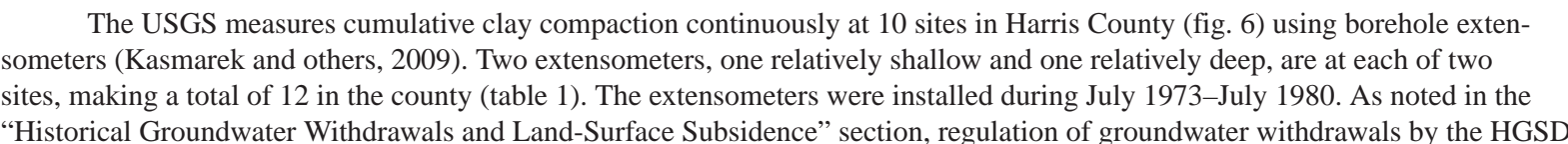

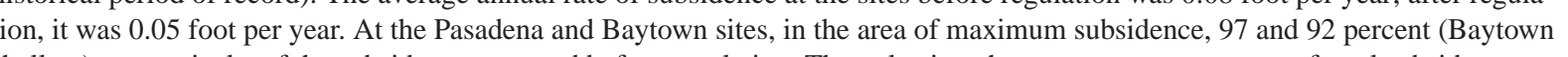

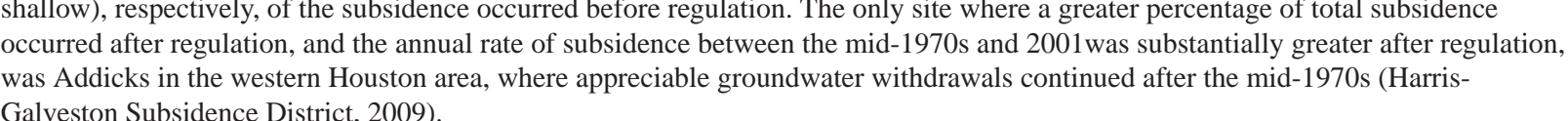

Summary

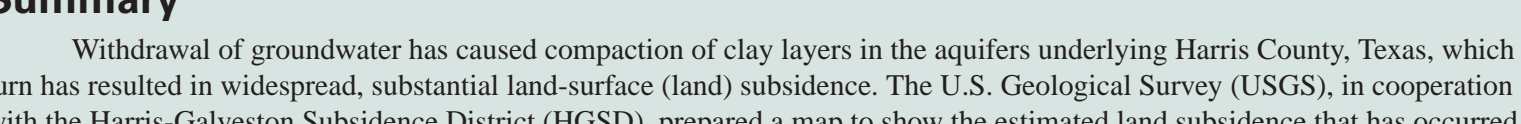

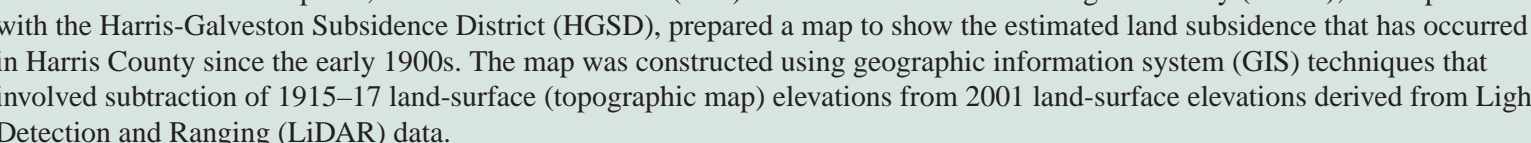

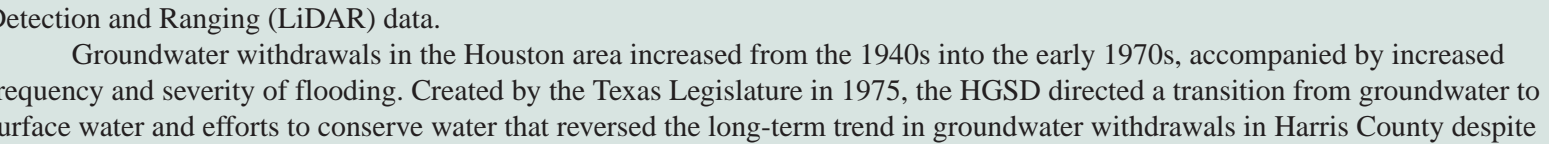

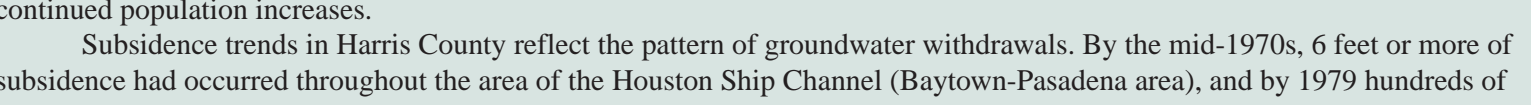

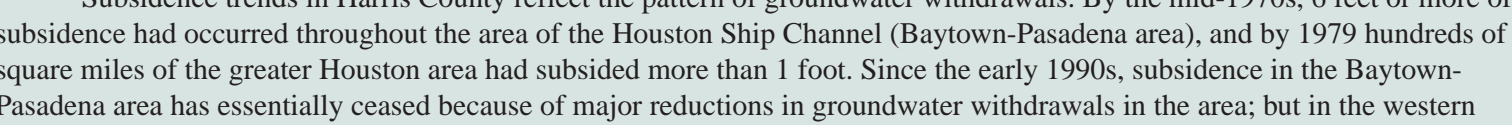

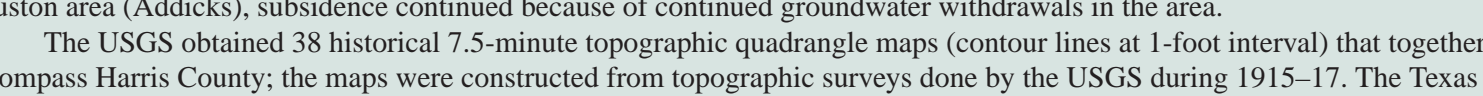

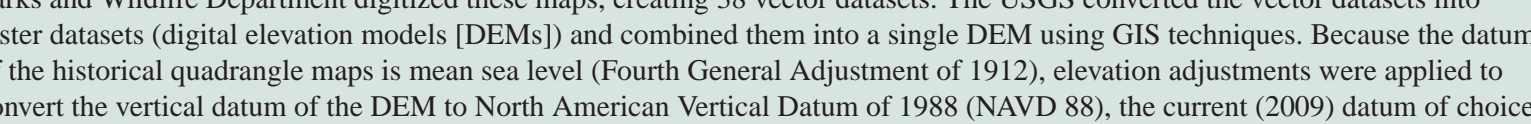

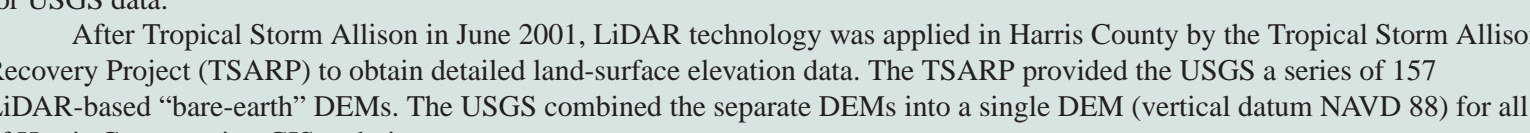

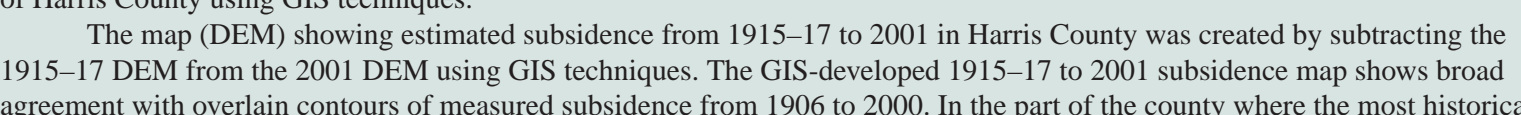

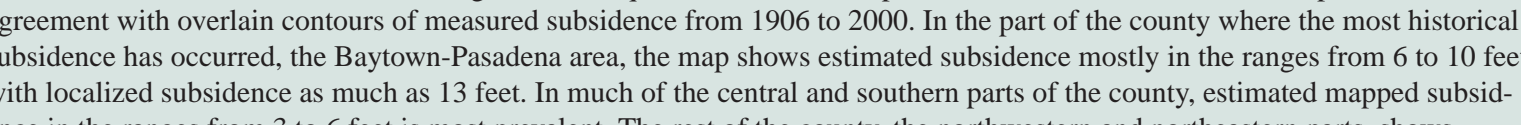

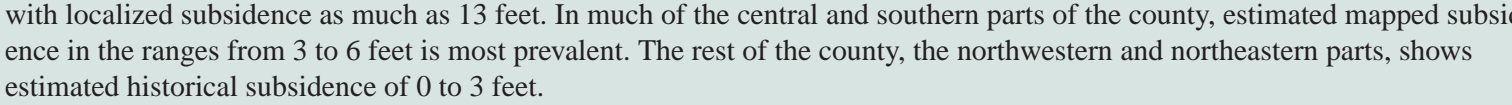

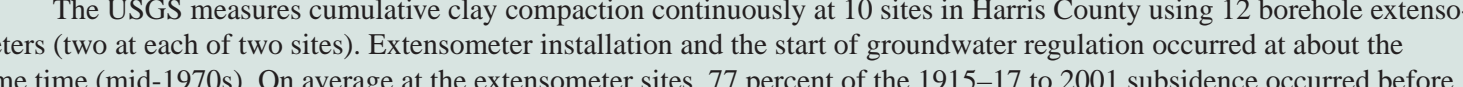

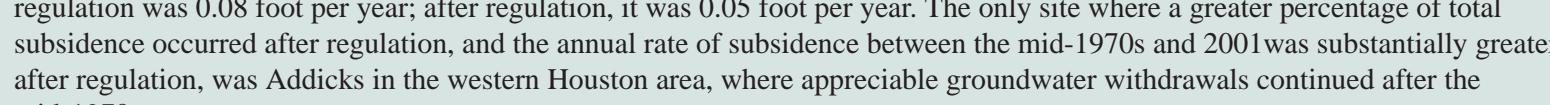

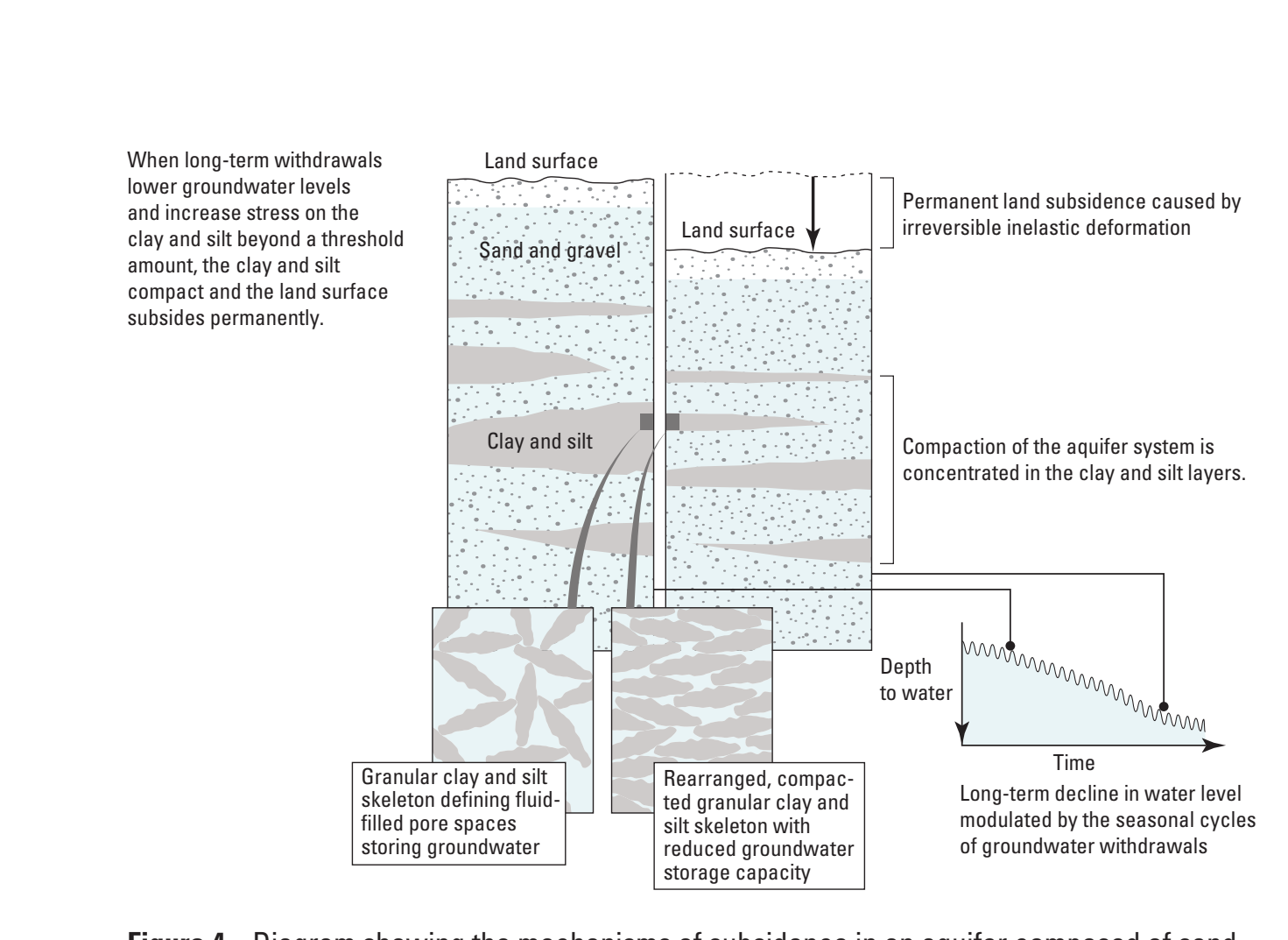

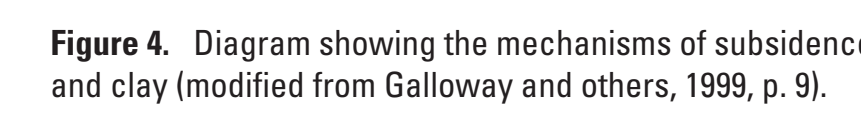

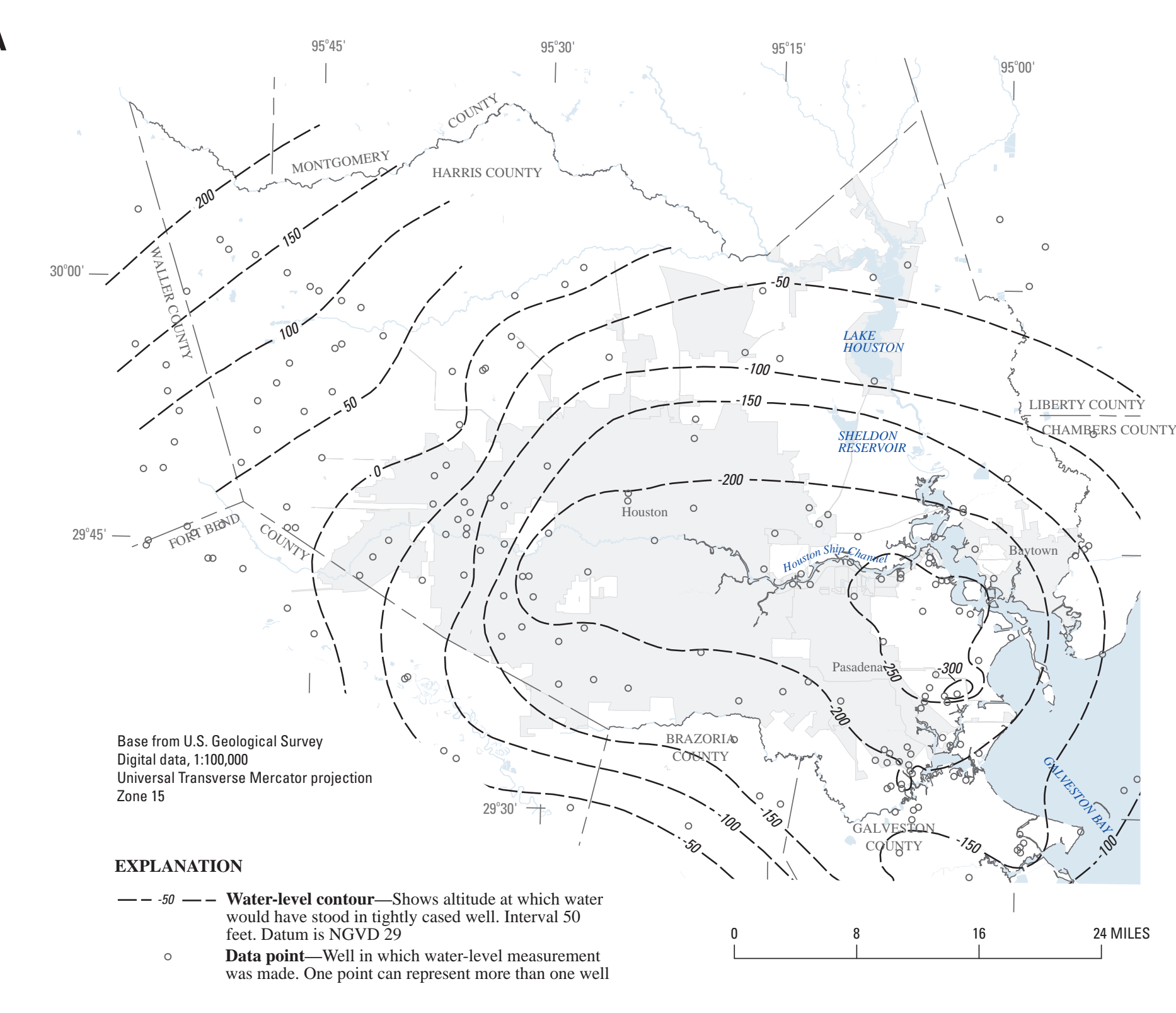

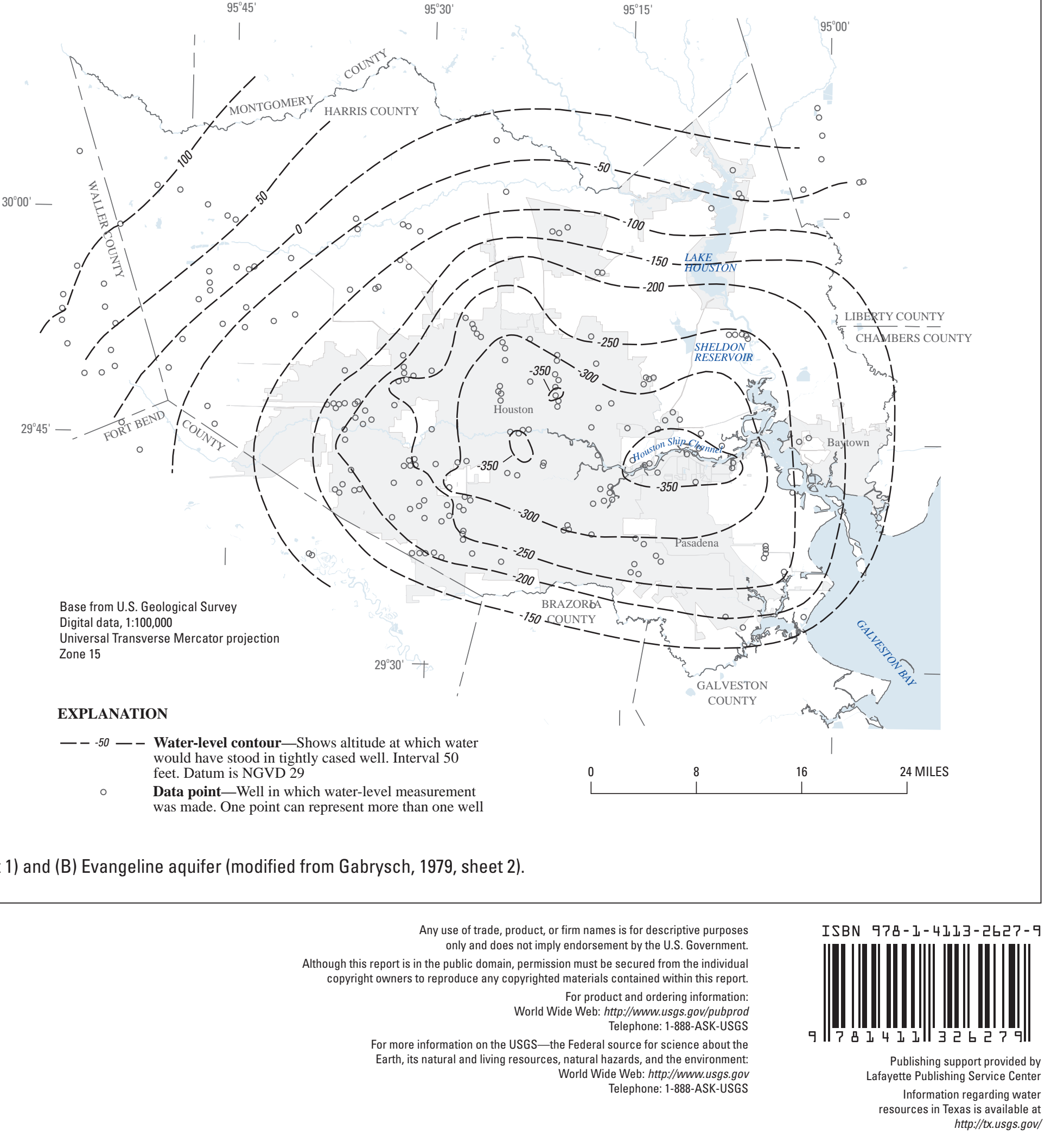

